\title{
Detection, analysis, and visualization of relevant scaffolds in medicinal chemistry project databases
}

\section{AM Clark}

Address: Chemical Computing Group Inc., Montreal, H3A 2R7, Canada

from 4th German Conference on Chemoinformatics

Goslar, Germany. 9-II November 2008

Published: 5 June 2009

Chemistry Central Journal 2009, 3(Suppl I):OI7 doi:I0.II86/I752-I53X-3-SI-OI7

This abstract is available from: http://www.journal.chemistrycentral.com/content/3/SI/OI7

(c) 2009 Clark; licensee BioMed Central Ltd.

Analysis of structure-activity relationships within lead optimization databases requires knowledge of each of the common scaffold substructures, an understanding of how the substitution sites map to each other, and an optimal assignment of scaffolds to input molecules in the event of ambiguity. We will present algorithms for solving each of these problems, which are capable of operating using only the molecules themselves as input, as well as being able to take into account any scaffold hints which may be known beforehand. Also discussed will be methods for depicting the resulting information in a visually intuitive way, as well as compilation of the results in the form of a report, which allows structure-activity trends to be examined interactively. 